\title{
Erratum to: Adjusting foraging strategies: a comparison of rural and urban common mynas (Acridotheres tristis)
}

Ira G. Federspiel ${ }^{1,2}$ - Alexis Garland ${ }^{1,3} \cdot$ David Guez $^{1,5}$ - Thomas Bugnyar ${ }^{2}$. Susan D. Healy ${ }^{4}$ - Onur Güntürkün ${ }^{3} \cdot$ Andrea S. Griffin $^{1}$

Published online: 16 January 2017

(C) Springer-Verlag Berlin Heidelberg 2017

\section{Erratum to: Anim Cogn}

DOI 10.1007/s10071-016-1045-7

In the original publication, the fourth author's name was incorrectly published as Thomas Bugynar. The correct name should read as Thomas Bugnyar.

The original article has been updated.

The online version of the original article can be found under doi:10.1007/s10071-016-1045-7.

Andrea S. Griffin

andrea.griffin@newcastle.edu.au

1 School of Psychology, University of Newcastle, Callaghan, NSW 2308, Australia

2 Department of Cognitive Biology, University of Vienna, Althanstrasse 14, 1090 Vienna, Austria

3 AE Biopsychologie, Fakultät für Psychologie, Ruhr-University Bochum, Bochum, Germany

4 School of Biology, University of St. Andrews, St Andrews, UK

5 Present Address: College of Healthcare Sciences, School of Psychology, James Cook University, P.O. Box 6811, Cairns, QLD 4870, Australia 